Full Length Article

\title{
Beneficiation of 6-0 mm fine-grain oil shale using vibrating air-dense medium fluidized bed separator
}

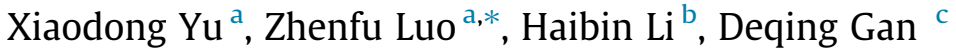 \\ ${ }^{a}$ School of Chemical Engineering E' Technology, China University of Mining and Technology, 221008 Xuzhou, China \\ ${ }^{\mathrm{b}}$ Qingdao Institute of Bioenergy and Bioprocess Technology, Chinese Academy of Sciences, 266101 Qingdao, China \\ ' College of Mining Engineering, North China University of Science and Technology, 063009 Tangshan, China
}

\section{H I G H L I G H T S}

- A VADMFB beneficiation process for oil shale of $6-0 \mathrm{~mm}$ was proposed.

- The probable error (E) was 0.125 when oil shale of 6-0 was cleaned by a VADMFB separator.

- The $6-0 \mathrm{~mm}$ oil shale can be beneficiated effectively by the VADMFB separator.

- The vibration intensity, air velocity, and bed height were systematically analyzed.

\section{A R T I C L E I N F O}

\section{Article history:}

Received 20 March 2017

Received in revised form 26 April 2017

Accepted 27 April 2017

\section{Keywords:}

Vibrating air-dense medium fluidized bed separator

Fine-grain oil shale

Dry beneficiation

Oil content
G R A P H I C A L A B S T R A C T

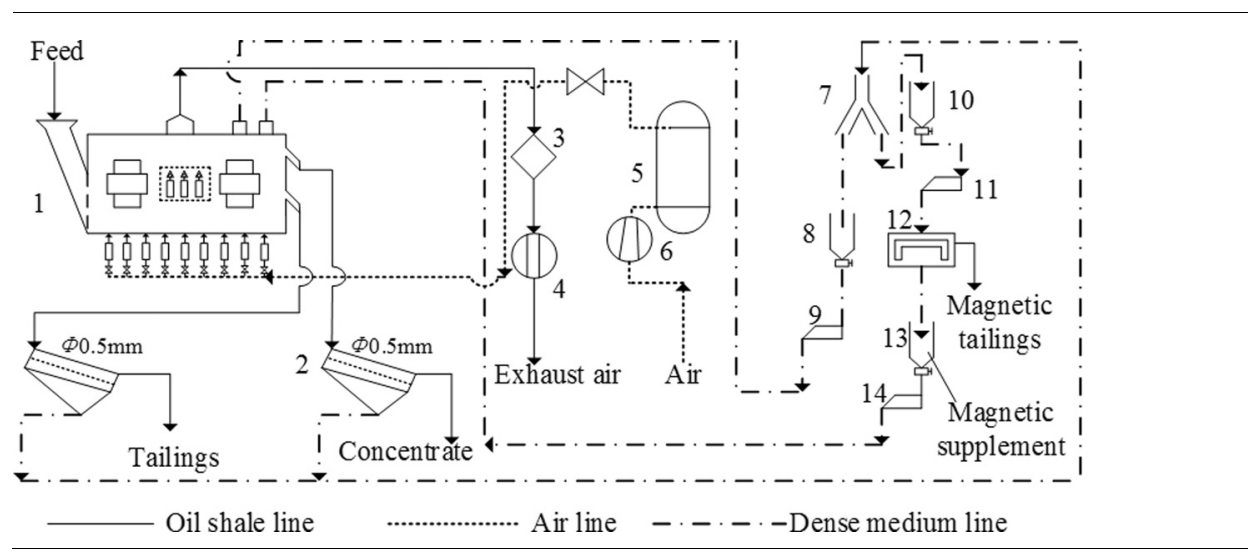

\begin{abstract}
A B S T R A C T
The throughput of oil shale is gradually increasing because of the high value it provides for different applications. However, during oil shale mining, a large amount of fine-grain $(6-0 \mathrm{~mm})$ material is produced. As the $6-0 \mathrm{~mm}$ material has higher oil content and better combustion performance, it can be effectively utilized by performing beneficiation through physical sorting to reduce impurities and upgrade the oil shale grade. In this paper, the physical properties of fine-grain $(6-0 \mathrm{~mm})$ oil shale were analyzed. The beneficiation of $6-0 \mathrm{~mm}$ oil shale using a vibrating air-dense medium fluidized bed was proposed. The effects of the vibration intensity $\Gamma$, gas velocity $v$, and bed height $h$ on the beneficiation efficiency were systematically investigated. The distribution characteristics of the oil content in the upper, middle, and lower layers of the bed under the optimum operating parameters were studied. Under the optimum operating parameters ( $v=1.46 \mathrm{~cm} / \mathrm{s}, h=85 \mathrm{~mm}, \Gamma=10.87$ ), the oil content in the upper layer material of the bed is uniform and the fluctuation of the oil content is gentle with better stability. The distribution of the oil content in the middle layer is disorderly, the fluctuation range expands further, and the stability is the worst. The oil content distribution in the lower layer material is uniform with a very small range of fluctuation, and the oil content distribution in the bed material is stable. The yields and oil content of the concentrate are $31.34 \%$ and $10.68 \%$, while those of tailings are $68.66 \%$ and $0.92 \%$, and the separating accuracy (probable error) is $0.125 \mathrm{~g} / \mathrm{cm}^{3}$. In conclusion, $6-0 \mathrm{~mm}$ oil shale can be effectively beneficiated by the vibrating air-dense fluidized bed separator and it can be recycled and utilized efficiently.

() 2017 Elsevier Ltd. All rights reserved.
\end{abstract}

\footnotetext{
* Corresponding author.

E-mail address: zfluo@cumt.edu.cn (Z. Luo).
} 


\section{Introduction}

Energy is an important prerequisite and foundation for human survival and social progress [1]. With scientific and economic development, the demand for energy is constantly increasing. However, the world is facing two major problems namely energy shortage and environmental degradation, both of which cannot be ignored [2]. Coal has always been considered as an important primary energy source supporting social and economic development $[3,4]$. With the rapid advancement of economy and technology, the demand for coal is bound to rise sharply, which will eventually lead to the total depletion of coal. To alleviate the problem of energy shortage, new sources of energy should be harnessed soon [5].

Oil shale is fine-grain sedimentary rock containing solid combustible organic matter in the mineral body. It is a special energy source with properties between those of coal and oil. A large amount of shale oil can be extracted out of this type of rock when the organic matter is pyrolyzed [6]. Enormous reserves of oil shale are available, and among fossil fuels, oil shale is second to coal in terms of calories. If it is converted into shale oil, the world's oil shale reserves will be 475 billion tons, equivalent to 5.4 times the world's proven recoverable natural oil reserves. Therefore, oil shale is an important potential source of energy [7]. With an increase in the use value of oil shale, its output is gradually increasing. During the mining process, fine-grain $(6-0 \mathrm{~mm})$ oil shale with a large amount of inorganic mineral impurities is produced. The fine-grain oil shale has a high oil content. If these granules are sorted and purified, we can effectively improve the dry distillation efficiency of oil shale, increase the economic value of shale ash, improve the comprehensive utilization efficiency of oil shale, reduce the processing cost, and reduce the environmental pollution, thus realizing the effective recovery and utilization of finegrain oil shale [8].

Oil shale is a high-density sorting material with a density around $2.35 \mathrm{~g} / \mathrm{cm}^{3}$. Some similarities exist in the physical properties between oil shale and coal; the principle of coal beneficiation provides insights that are relevant to oil shale separation processes $[9,6]$. The selection of the sorting process directly determines the quality of the product; separation processes that use a large amount of water mainly include the jigging washing process and heavy medium separation. Both these processes are barely able to provide the required oil shale separation density, and therefore ineffective with respect to the separation effects and inadequate for oil shale upgrading [10-14]. The oil content is inversely proportional to the density of oil shale. The density of inorganic mineral impurities is higher, and these impurities should be discarded to obtain pure oil shale with low density. Oil shale can be separated effectively from inorganic mineral impurities by dry separation methods. Existing researches on the dry sorting of oil shale show that the separation of $>6 \mathrm{~mm}$ coarse-grain oil shale using a compound dry separator is more successful and can provide purer oil shale products. However, studies concerning 6-0 mm oil shale sorting process are few. In this paper, based on the physical properties of fine-grain oil shale, we proposed the use of vibrating air-dense medium fluidized bed (VADMFB) separation to beneficiate oil shale. The effects of the main factors including the vibration intensity, airflow, and bed height on oil shale separation were systematically investigated and the optimal operational parameters were identified in the laboratory separation process. The paper is expected to provide technological support for the promotion of fine-grain oil shale dry beneficiation technologies in industries.

\section{Experimental}

\subsection{Dry separation apparatus}

Fig. 1 shows the fine-grain oil shale VADMFB sorting system. The raw ore is separated in the VADMFB before it is conveyed to the surge bin. The density of the bed is controlled by adjusting the density control device to make the light material float and the heavy material sink. The light and heavy materials are discharged by the discharge device, and disassembled through the release screen with a diameter of $0.5 \mathrm{~mm}$. The screen overflow material becomes the final concentrate and tailings, and the screen underflow magnetic material is diverted by a diverter. A portion of magnetic material is recovered into heavier medium by a dry magnetic separator, and the other part directly returns to the VADMFB

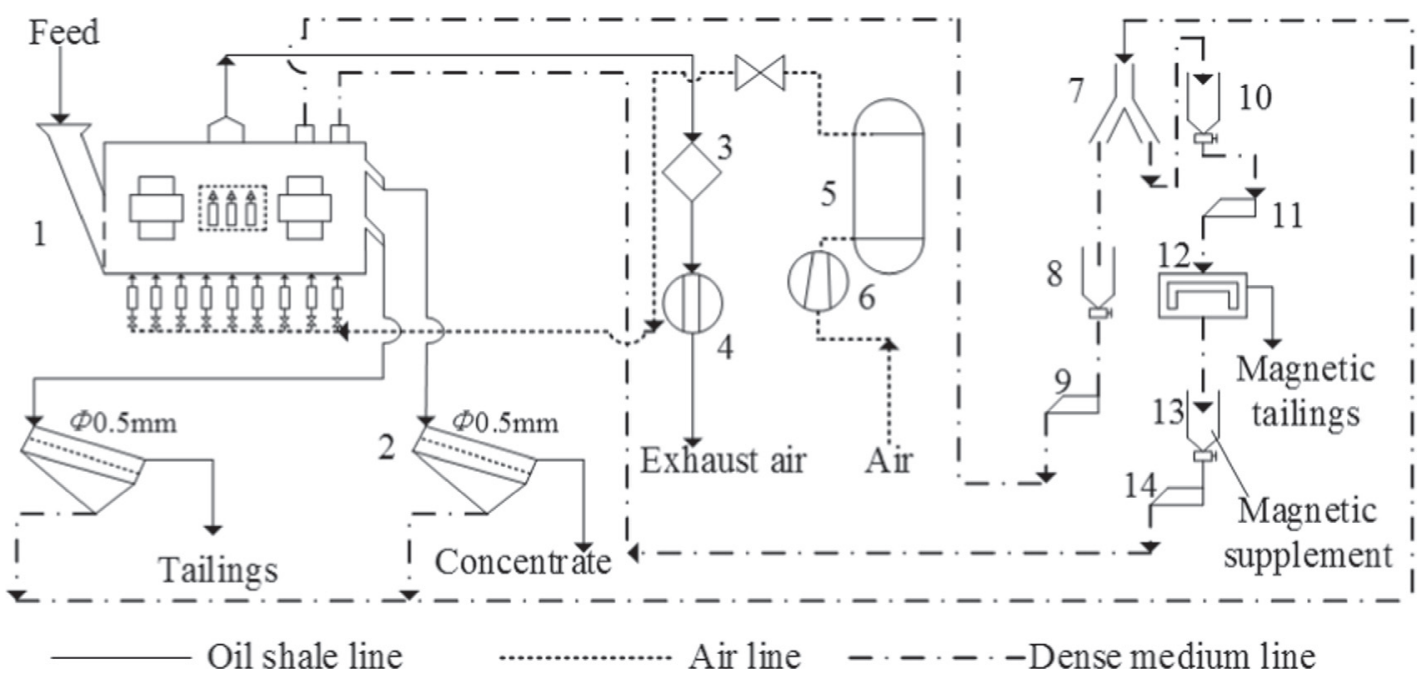

1-VADMFB separator, 2-scalping screen $(\phi 0.5 \mathrm{~mm})$, 3-dust collector, 4-induced draft fan, 5-air bag,

6-air blower, 7-diverter, 8-cycling medium bin, 9-feeder, 10-cycling medium bin, 11-feeder,

12-magnetic separator, 13-medium bin, 14-medium feeder

Fig. 1. Diagram of oil shale VADMFB dry beneficiation system. 
for reuse. The fluidizing gas required during the sorting process is provided by the Roots blower. The dust produced by the sorting process is accumulated by the dust collector to release the effluent gas into the atmosphere.

\subsection{Material properties}

Physical properties of oil shale affect the beneficiation results. The oil content is inversely proportional to the density of oil shale, a high-density mineral. However, these properties are related to the microstructure and mineral elements of oil shale. Therefore, it is necessary to analyze the inorganic mineral elements contained in oil shale and then reveal the physical characteristics of oil shale to provide technical support for the sorting. At present, in most studies, the oil content and the calorie value are considered as the oil shale classification standards. In this paper, oil content is considered as the classification standard and is expressed by " $\omega$ ". The oil content in crude ore is $3.96 \%$. A scanning electron microscope and an energy dispersive spectrometer are also used to analyze the surface morphological structure, density and oil content characteristics of the concentrate $(\omega \geq 10 \%)$, tailings $(0 \leq \omega \leq 3 \%)$, and crude ore $(\omega \leq 5 \%)$. The aluminum retort analysis results, element analysis results and sink-float test results of oil shale are listed in Tables 1-3. Based on the sink-float test results, the washability curves are shown in Fig. 2. The true density, bulk density and dominant size range of the dense medium (ferrosilicon powder) are $6.87 \mathrm{~g} / \mathrm{cm}^{3}, 3.15 \mathrm{~g} / \mathrm{cm}^{3}$ and $0.074-0.045 \mathrm{~mm}$. The ferrosilicon powder has a silicon content of $75 \%$ and an iron content of $25 \%$. The size range of the ferrosilicon powder is shown in Fig. 3.

\subsection{Evaluation}

The purpose of oil shale beneficiation is to enrich organic matters, raise the grade of oil shale and increase its oil content. Accord-

Table 1

Results of oil shale aluminum retort analysis.

\begin{tabular}{lllll}
\hline $\begin{array}{l}\text { Material } \\
\text { name }\end{array}$ & $\begin{array}{l}\text { Oil content } \\
(\%)\end{array}$ & $\begin{array}{l}\text { Char content } \\
(\%)\end{array}$ & $\begin{array}{l}\text { Moisture content } \\
(\%)\end{array}$ & $\begin{array}{l}\text { Gas loss } \\
(\%)\end{array}$ \\
\hline Concentrate & 10.68 & 79.23 & 1.98 & 5.98 \\
Tailings & 0.92 & 93.15 & 2.04 & 2.78 \\
Crude ore & 3.96 & 89.67 & 2.02 & 4.23 \\
\hline
\end{tabular}

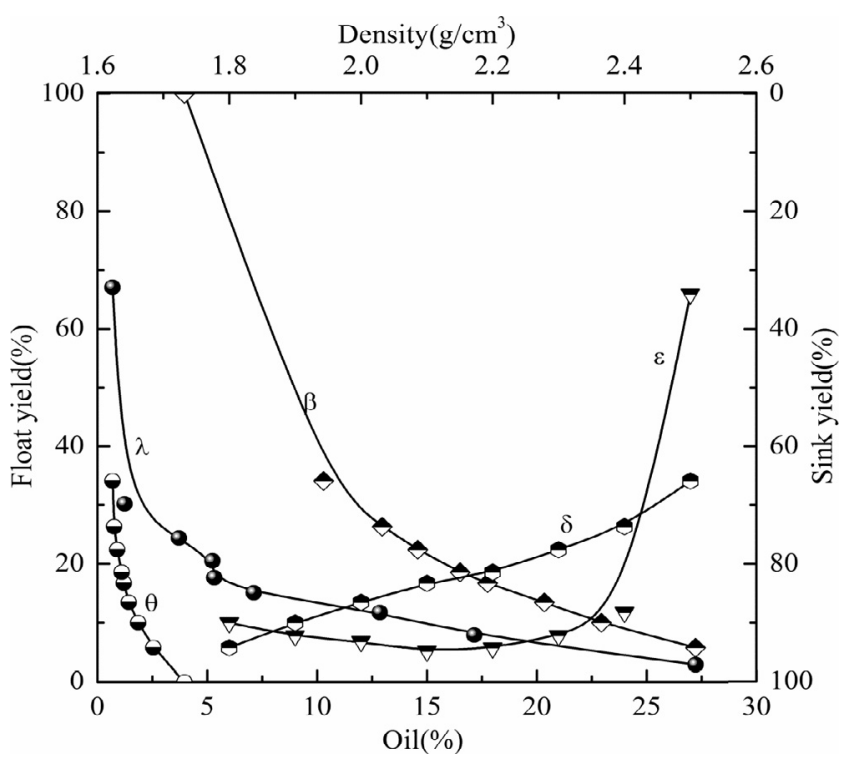

Fig. 2. Washability curves of oil shale with grain size of 6-0 mm.

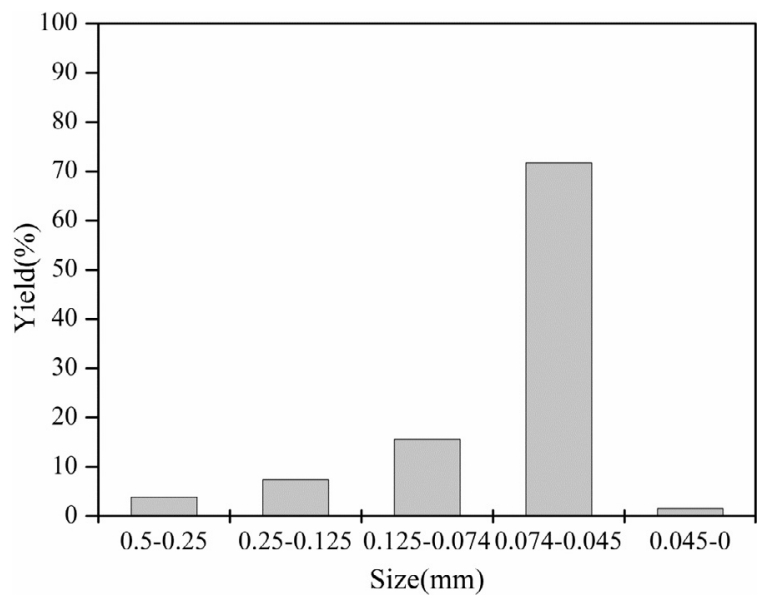

Fig. 3. Grain size composition of dense medium.

Table 2

Results of oil shale elemental analysis.

\begin{tabular}{|c|c|c|c|c|c|c|c|c|c|c|}
\hline Material name & $\mathrm{C}(\%)$ & $\mathrm{O}(\%)$ & $\mathrm{Al}(\%)$ & Si (\%) & $\mathrm{Na}(\%)$ & $\mathrm{K}(\%)$ & $\mathrm{Fe}(\%)$ & $\mathrm{Ti}(\%)$ & $\mathrm{S}_{\mathrm{t}, \mathrm{d}}(\%)$ & $\operatorname{Mg}(\%)$ \\
\hline Concentrate & 51.55 & 25.85 & 4.85 & 13.21 & 1.55 & 1.75 & 1.23 & 0.02 & 0.05 & 0.03 \\
\hline Tailings & 15.20 & 50.10 & 7.46 & 8.09 & 2.08 & 0.94 & 2.74 & 1.64 & 4.41 & 2.92 \\
\hline Crude ore & 27.18 & 39.82 & 5.66 & 19.56 & 1.91 & 2.34 & 1.72 & 1.21 & 0.08 & 0.12 \\
\hline
\end{tabular}

Table 3

Results of sink-float test for $6-0 \mathrm{~mm}$ oil shale.

\begin{tabular}{|c|c|c|c|c|c|c|c|c|}
\hline \multirow[t]{2}{*}{ Density $\left(\mathrm{g} / \mathrm{cm}^{3}\right)$} & \multirow[t]{2}{*}{ Yield (\%) } & \multirow[t]{2}{*}{ Oil content (\%) } & \multicolumn{2}{|c|}{ Float Products } & \multicolumn{2}{|c|}{$\underline{\text { Sink Products }}$} & \multicolumn{2}{|l|}{$\delta_{\mathrm{p}} \pm 0.1$} \\
\hline & & & Yield (\%) & Oil content (\%) & Yield (\%) & Oil content (\%) & Density $\left(\mathrm{g} / \mathrm{cm}^{3}\right)$ & Yield (\%) \\
\hline-1.8 & 5.73 & 27.23 & 5.73 & 27.23 & 100.00 & 3.96 & 1.8 & 9.98 \\
\hline $1.8-1.9$ & 4.25 & 17.16 & 9.98 & 22.94 & 94.27 & 2.55 & 1.9 & 7.73 \\
\hline $1.9-2.0$ & 3.48 & 12.86 & 13.46 & 20.34 & 90.02 & 1.86 & 2.0 & 6.73 \\
\hline $2.0-2.1$ & 3.25 & 7.12 & 16.71 & 17.76 & 86.54 & 1.42 & 2.1 & 5.12 \\
\hline $2.1-2.2$ & 1.87 & 5.32 & 18.58 & 16.51 & 83.29 & 1.20 & 2.2 & 5.68 \\
\hline $2.2-2.3$ & 3.81 & 5.23 & 22.39 & 14.59 & 81.42 & 1.10 & 2.3 & 7.76 \\
\hline $2.3-2.4$ & 3.95 & 3.71 & 26.34 & 12.96 & 77.61 & 0.90 & 2.4 & 11.71 \\
\hline $2.4-2.5$ & 7.76 & 1.23 & 34.10 & 10.29 & 73.66 & 0.75 & 2.5 & 65.90 \\
\hline+2.5 & 65.90 & 0.69 & 100.00 & 3.96 & 65.90 & 0.69 & & \\
\hline Total & 100.00 & 3.96 & & & & & & \\
\hline
\end{tabular}




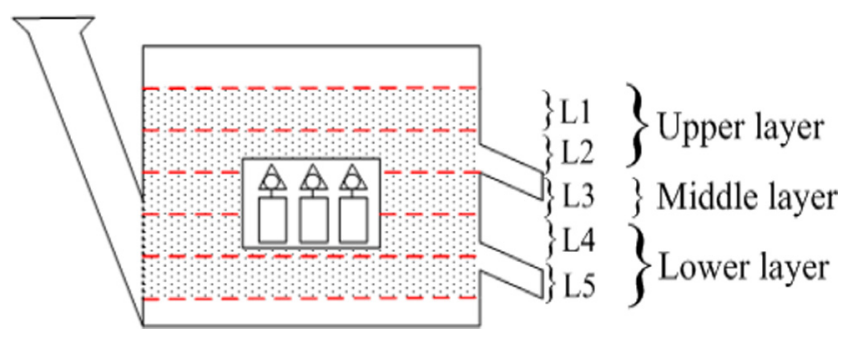

Fig. 4. Diagram showing stratified sampling for beneficiation.

ing to the physical properties of oil shale, the oil content in oil shale decreases with an increase in its density. Therefore, the VADMFB beneficiation by the density sorting process aims to enrich the oil content. Fig. 4 indicates that the VADMFB separator is divided into five parts along the height of the bed. This allows for the derivation of different products, whose yields and oil content can be measured. The oil segregation intensity is defined as follows [15]:

$S_{o}=\sqrt{\frac{1}{n} \sum_{i=1}^{n}\left(\omega_{i} / \omega_{o}-1\right)^{2}}$

where $\omega_{i}$ is the oil content in the $i$ th layer (\%), $\omega_{o}$ is the oil content in the feed oil shale (\%), and $n$ is the sampling number. This parameter illustrates the deviation intensity of the oil content in layer $i$ from the oil content in the feed ore. Better beneficiation results will be obtained as the oil segregation intensity $S_{o}$ becomes higher. In the case of VADMFB separator, concentrate with higher oil content is found in the upper bed, and gangue with lower oil content is found in the bottom bed. Fig. 4 shows the sampling method used in the separator.

The beneficiation process of the VADMFB separator depends on the density and the oil content. The oil content distribution in the material on the bed can directly indicate material movement and beneficiation effect at a particular point in time. Therefore, the measurement of the material oil content on the bed can provide clearer beneficiation results, and optimize the beneficiation conditions and results. To simplify the study of oil content distribution on the bed, a base coordinate system is set up, as shown in Fig. 5. The X-axis extends from the feed end to the discharge end, and the bed in this direction is divided into 18 equal parts. The $\mathrm{X}$ - and $\mathrm{Y}$-axes are perpendicular to each other and lie on the same horizontal plane. The bed in the Y direction is divided into 4 equal parts. The material is sampled at the cross region, where the oil content is measured.

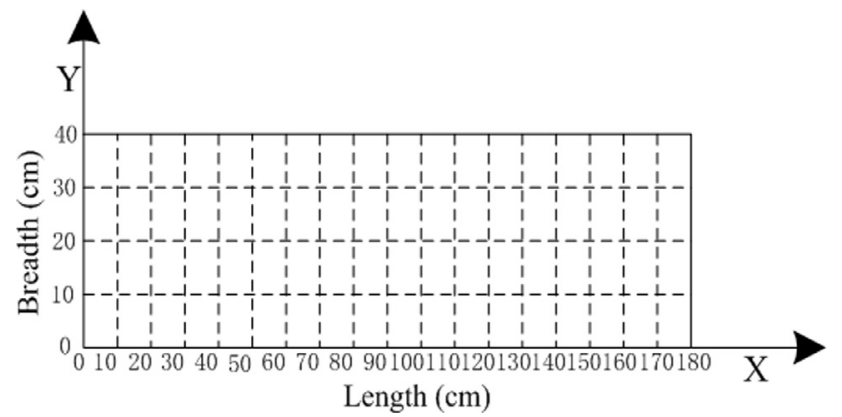

Fig. 5. Distribution of sampled material on VADMFB separator bed for oil content measurement.

\section{Results and discussion}

\subsection{Physical properties of oil shale}

As can be seen in Fig. 6, the inorganic minerals of the concentrate are mainly aluminum and silicon elements. The inorganic minerals of the tailings also contain silicon and aluminum elements, as well as a small amount of sodium, potassium, iron, and other non-metallic elements. This indicates that the oil shale oil content and the inorganic mineral content are directly related. The higher the oil content, the lower the inorganic mineral content. And the lower the oil content, the greater the amount of inorganic mineral elements.

\subsection{Effects of air velocity on beneficiation}

The effects of air velocity on the VADMFB separator are investigated when the vibration intensity is $7.39(A=1.5 \mathrm{~mm}, f=35 \mathrm{~Hz})$, bed height is $80 \mathrm{~mm}$, and separation time is $90 \mathrm{~s}$. The results are shown in Fig. 7.

The intensity of segregation with respect to the air velocity in Fig. 7 shows the difference between the oil content in different bed layer particles and that in the raw ore. A higher deviating amplitude in the oil content curves between each layer and the run-of mine indicates a bigger oil content discrepancy, which also means better sorting effect and higher beneficiation efficiency. In contrast, a lower deviating amplitude indicates worse beneficiation effect. When the gas velocity is $0.75 \mathrm{~cm} / \mathrm{s}$, the oil content curves of each layer deviates slightly from that of the raw mine, which indicates worse beneficiation effect. This is because when the fluidization air velocity is low, the gas fraction is low, which leads to a low bed expansion ratio [16]. In this case, the effect of the drag force of the fluidization gas on the particles is minor, and a low particle concentration implies a big resistance of particle movement, which leads to bad layering effect. As the air velocity and the bed expansion ratio increase, the drag force increases, the resistance of particle movement decreases, and the layering effect gradually becomes evident. When the air velocity is $1.46 \mathrm{~cm} / \mathrm{s}$, the deviating amplitude becomes maximum and the segregation intensity of the oil content reaches its largest value of 1.21 , which means that in this condition, the beneficiation effect is optimal. When the air velocity increases further, the deviating amplitude of the oil content curves decreases gradually. When the air velocity is very large, the excess gas passes into the bed and some local areas generate a large number of bubbles. As the bubbles rise, they destabilize the particle bed seriously, which causes particles circulation and back-mixing and leads to a bad beneficiation effect. When the air velocity is $2.01 \mathrm{~cm} / \mathrm{s}$, the layering effect is the worst.

\subsection{Effects of bed height on beneficiation}

The effects of the bed height on the VADMFB separator are also investigated when the vibration intensity is $7.39(A=1.5 \mathrm{~mm}$, $f=35 \mathrm{~Hz}$ ), air velocity is $1.46 \mathrm{~cm} / \mathrm{s}$, and separation time is $90 \mathrm{~s}$. The results are shown in Fig. 8.

Figs. 8 and 9 show that when the bed height is $75 \mathrm{~mm}$, the oil content in the L1, L2, L4, and L5 layers is close to that in the raw ore and the corresponding oil segregation intensity values are relatively small, with $S_{o}$ being 1.02 , which indicates that the material stratification is poor. The vibration energy transfer along the bed height is accompanied by energy diffusion. The vertical flow of the fluidizing gas through the bed becomes shorter and the resistance of the particles is greatly reduced when the bed height is low, which cuts down the bed expansion, and hence, a reliable flu- 

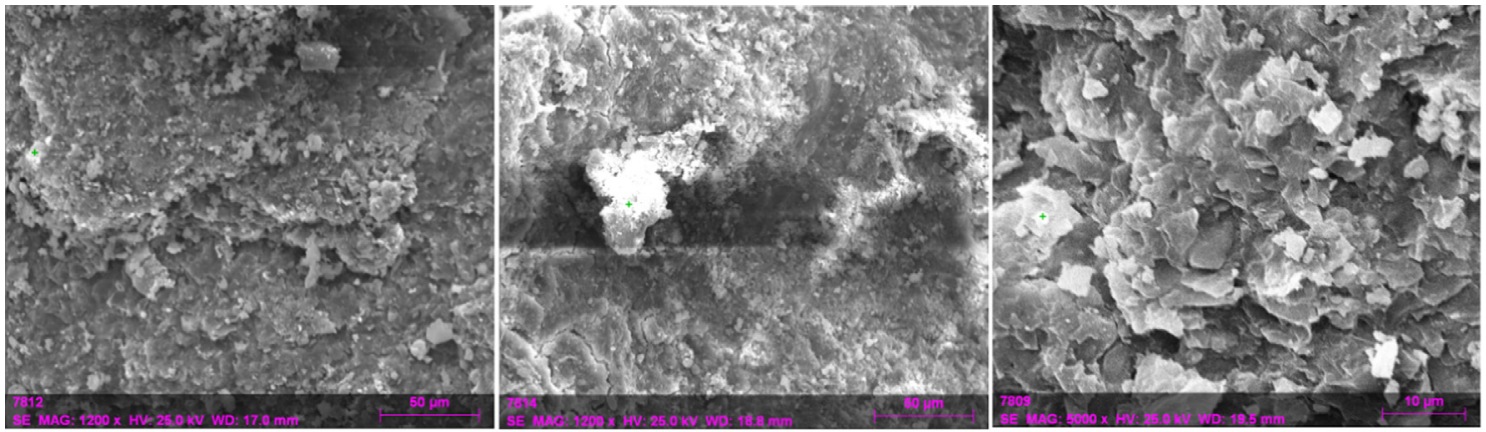

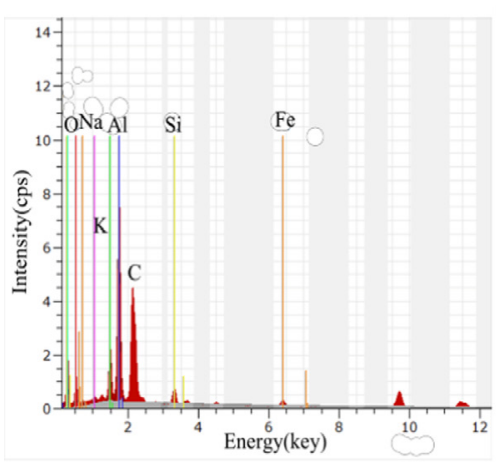

(a) $\omega>10 \%$

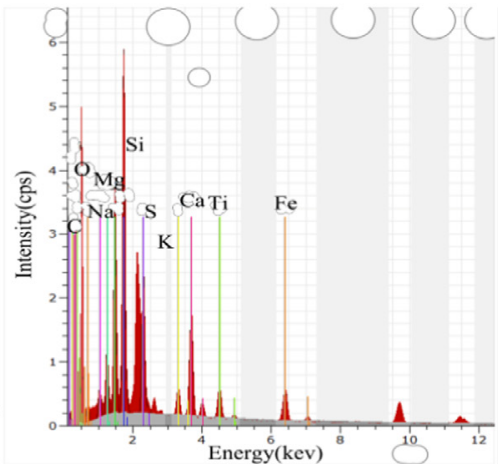

(b) $3 \%>\omega>0$

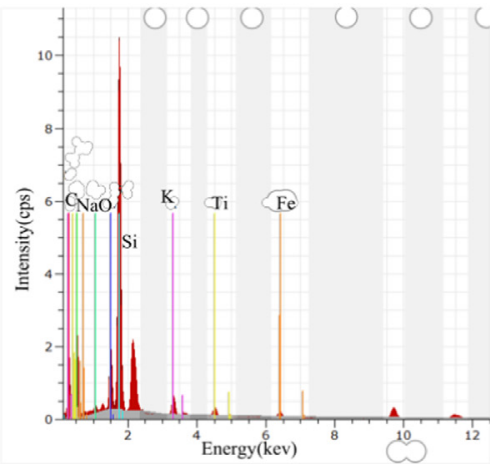

(c) $5 \%>\omega \geq 3 \%$

Fig. 6. Elemental analysis and microstructure of oil shale with different oil contents.

idization environment for material segregation according to the bed density cannot be provided $[17,18]$. With an increase in the air velocity, the vertical path of the fluidized gas through the bed becomes longer and the particle resistance increases. Then, the fluidized environment can be changed. When the bed height is $85 \mathrm{~mm}$, the material oil content in the L1, L2, L3, L4, and L5 layers shows the greatest differences compared to the oil content in the raw ore. In this condition, the value of the oil segregation intensity $S_{o}$ is 1.16 which is the maximum, illustrating that the material is evenly distributed in each layer and that the optimum stratification is obtained. With a further increase in the bed height, the differences between the oil content in the material in all layers and the oil content in the raw ore are reduced and the value of the oil segregation intensity decreases, which indicates that the bed height is very large. At larger bed height, the effect of vibration on the promotion of fluidization is generally weaker. The residence time of the bubbles in the bed is prolonged, and the bubbles continue to grow and then spread into a number of big bubbles with irregular movement, which results in back-mixing, circulation of larger-size particles, and deterioration of the segregation effect of the bed density. The minimum oil segregation intensity value of 0.84 is achieved when the bed height increases to $95 \mathrm{~mm}$, indicating that the stratification effect is the worst.

\subsection{Effects of vibration intensity on beneficiation}

Vibration provides energy to the material sorting process and plays an important role in sorting. The effect of vibration intensity is studied when the air velocity is $1.46 \mathrm{~cm} / \mathrm{s}$, the sorting time is $90 \mathrm{~s}$, and the bed height is $80 \mathrm{~mm}$. The vibration energy magnitude is expressed by vibration intensity, which is a combination of amplitude and frequency. The same vibration intensity can be a combination of different amplitudes and frequencies. Therefore, to achieve a suitable sorting effect, it is important to determine the optimal combination of amplitude and frequency. Table 4 lists the different vibration conditions for the oil segregation intensity. Fig. 10 shows the contour map of the corresponding vibration intensities for the oil segregation intensity.

Fig. 10 shows the contour map for the $6 \mathrm{~mm}$ oil shale under different vibration conditions. As shown in the figure, the beneficiation of oil shale can be realized in the optimal vibration parameter range, in which the vibration amplitude and the vibration frequency are both adjusted to lie in the middle of their range of values and the oil segregation intensity is greater than 0.67 . This directly shows that the vibration intensity has a significant effect on the density segregation of the oil content. As can be seen from the contour map, the ranges of the vibration frequency $f$, amplitude $A$, and corresponding vibration intensity $\Gamma$ are $27-42 \mathrm{~Hz}, 2.2-$ $3.1 \mathrm{~mm}$, and $6.45-22.01$, respectively. When the amplitude $A$ is changed between 2.2 and $3.1 \mathrm{~mm}$, the oil segregation intensity of the particle first increases and then decreases with a rise in frequency. The vibration frequency determines the air pressure wave frequency, which in turn determines the number of flat bubbles generated per unit time and the number of bubbles in a given height. With an increase in the vibration frequency, the number of bubbles generated per unit time increases and the number of bubble groups that occur in a certain area increases. Consequently, the height of the sorting disturbance area increases. To achieve the optimal sorting condition for the fluidized bed, a suitable height is required for the disturbance area. In addition, a perfect fluidization space cannot be formed when the height is very large or very small and a good beneficiation cannot be achieved. Therefore, the optimal ranges of $f, A$, and $\Gamma$ are $27-42 \mathrm{~Hz}, 2.2-3.1 \mathrm{~mm}$, and $6.45-$ 22.01 , respectively. Under these conditions, the optimum material oil segregation intensity and sorting efficiency can be obtained.

\subsection{Determination of optimal operation parameters}

The effects of the vibration intensity, airflow, and bed height on the oil shale beneficiation using the VADMFB separator based on 

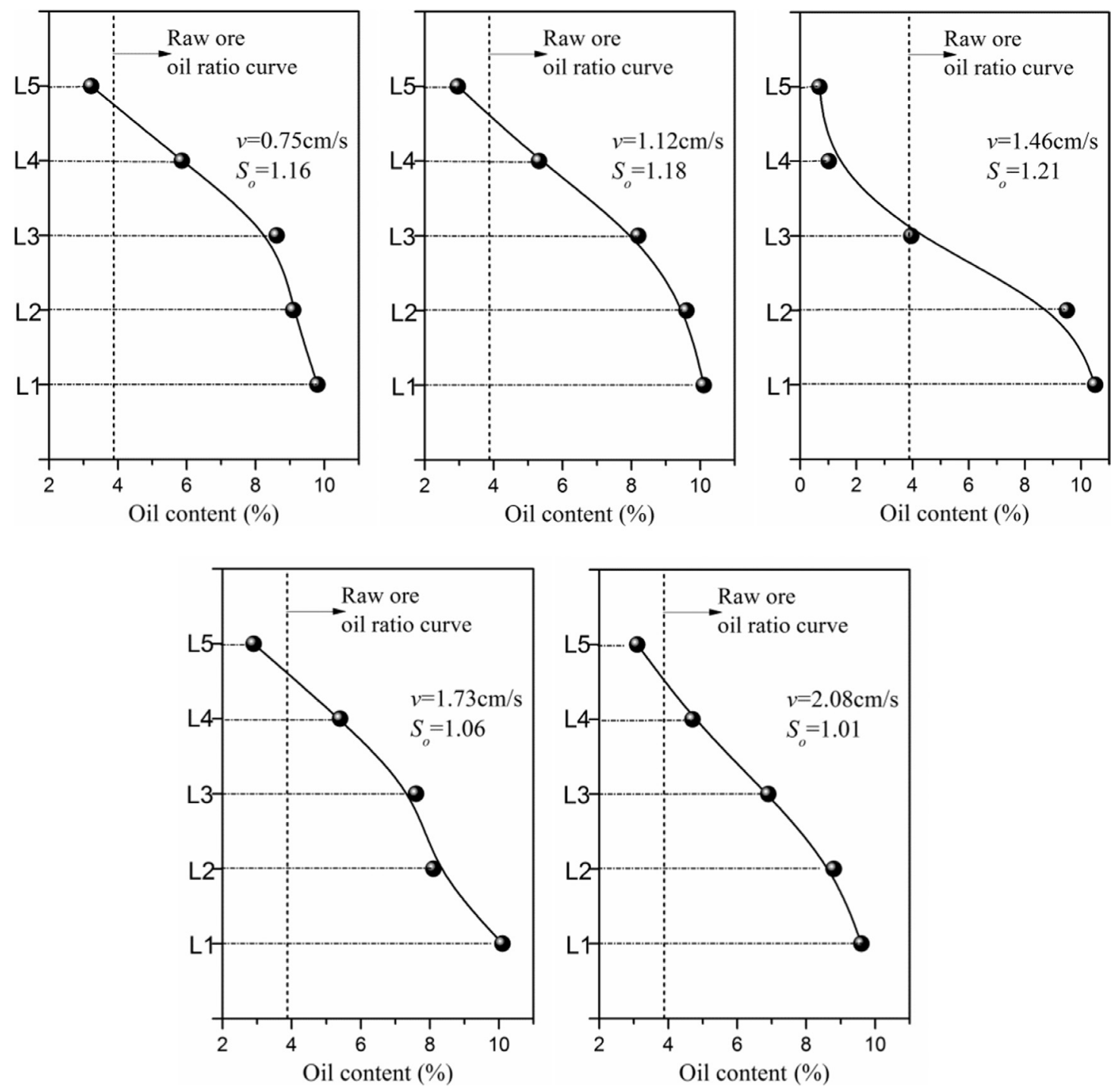

Fig. 7. Segregation patterns of oil shale at different air velocities.

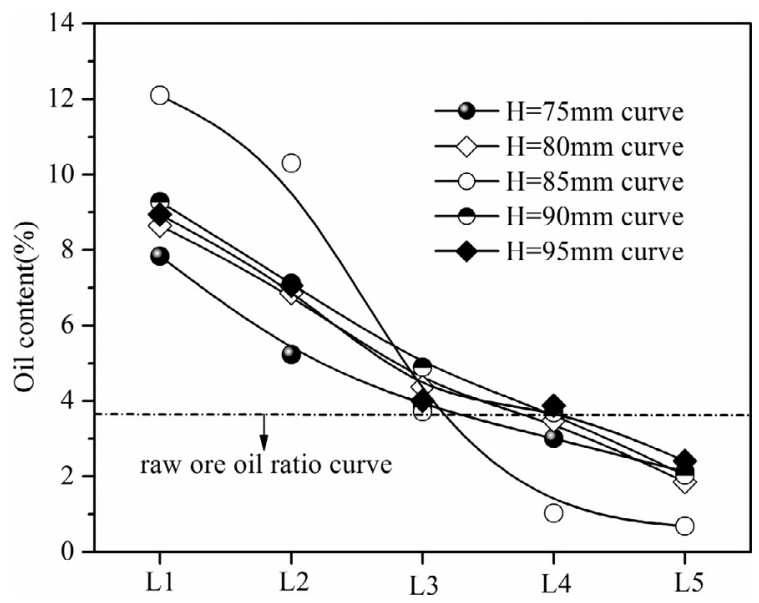

Fig. 8. Segregation patterns of oil shale at different bed heights.

single-factor experiments have been discussed in previous sections to study the significance of these parameters on the separation and interaction of parameters. To determine the optimal operating

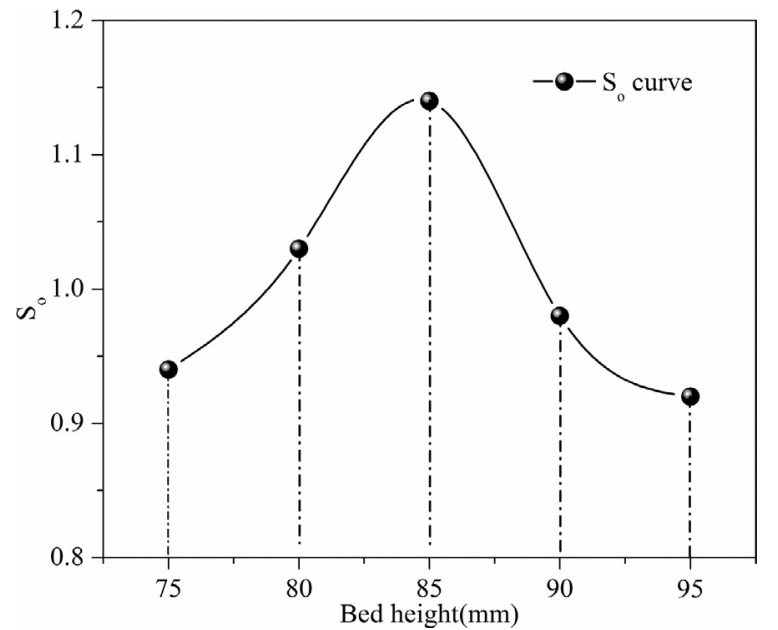

Fig. 9. Effects of bed height on beneficiation content in VADMFB separator.

parameters, a response surface method is utilized for the analysis of the segregation intensity. The relationship between the segregation intensity and the parameters is studied. The experimental 
Table 4

Oil segregation intensity $S_{o}$ under different vibration conditions.

\begin{tabular}{llll}
\hline$f(\mathrm{HZ})$ & $A(\mathrm{~mm})$ & $\Gamma$ & $S_{\text {oil }}$ \\
\hline 15 & 0.75 & 0.68 & 0.36 \\
15 & 1.5 & 1.36 & 0.45 \\
15 & 2.5 & 2.26 & 0.68 \\
15 & 3.5 & 3.17 & 0.51 \\
25 & 0.75 & 1.89 & 0.41 \\
25 & 1.5 & 3.77 & 0.52 \\
25 & 2.5 & 6.29 & 0.69 \\
25 & 3.5 & 8.80 & 0.39 \\
35 & 0.75 & 3.70 & 0.54 \\
35 & 1.5 & 7.39 & 0.71 \\
35 & 2.5 & 12.32 & 0.68 \\
35 & 3.5 & 17.25 & 0.49 \\
45 & 0.75 & 6.11 & 0.41 \\
45 & 1.5 & 12.22 & 0.68 \\
45 & 2.5 & 20.37 & 0.53 \\
45 & 3.5 & 28.52 & 0.44 \\
\hline
\end{tabular}

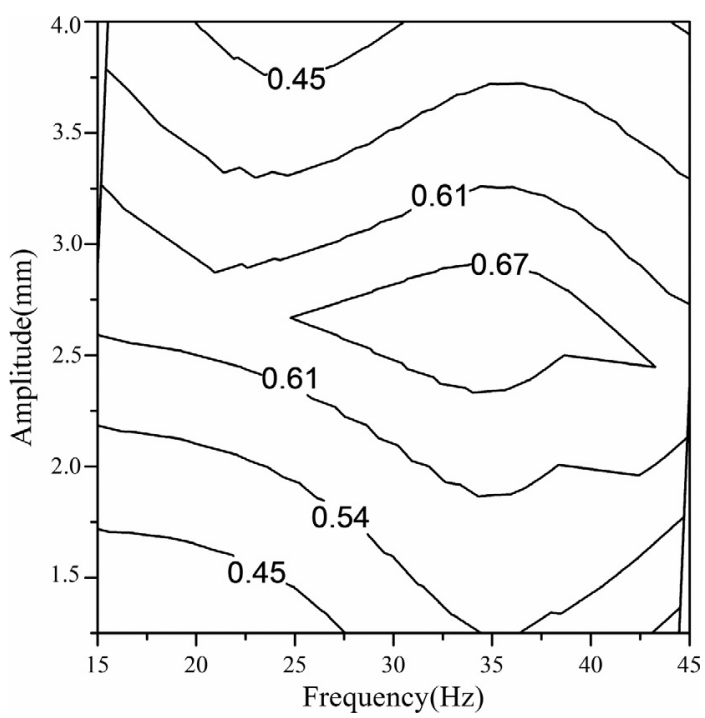

Fig. 10. Contour map of vibration intensity with respect to vibration conditions.

designs for the response surface method and the model analysis are summarized in Tables 5 and 6.

As deduced from Table 6, the quadratic polynomial model is recommended. The Prob $>F$ values are considerably less than 0.5 , suggesting that the response surface model has a greater fitting

Table 5

Basic operation parameters in the beneficiation experiments.

\begin{tabular}{llllll}
\hline Code & Factors & Unit & Minimum & Maximum & Level \\
\hline A & Air velocity & $\mathrm{cm} / \mathrm{s}$ & 0.75 & 2.01 & 3 \\
B & Bed height & $\mathrm{mm}$ & 75 & 95 & 3 \\
C & Vibration intensity & & 4.69 & 17.04 & 3 \\
\hline
\end{tabular}

accuracy. The results of an analysis of variance for the recommended quadratic polynomial model are summarized in Table 7.

Table 7 indicates that the $\mathrm{F}$ value of the quadratic polynomial model is 24.04, which indicates that the effects of combinations of factors on the segregation intensity are significant. The Prob $>\mathrm{F}$ values for the investigated items $\mathrm{A}, \mathrm{B}, \mathrm{C}, \mathrm{BC}, \mathrm{A}^{2}, \mathrm{~B}^{2}$, and $\mathrm{C}^{2}$ are less than 0.05 , indicating that the items have a marginal impact on the segregation intensity. Further, the values of $\mathrm{R}^{2}$, corrected $\mathrm{R}^{2}$, and the deviation coefficient are $0.9687,0.9284$ and 0.018 , respectively, indicating that the recommended model has high credibility.

The response surface for the effects of the vibration intensity, bed height and air velocity on the segregation intensity is shown in Fig. 11. In addition, the contours for different operating conditions are also illustrated.

The response surface is very steep in the vibration intensity direction, as shown in Fig. 11(a). The results show that the variation of vibration intensity has a great influence on the fluctuation of bed density in a VADMFB. Further, the bed density directly affect the distribution and segregation of oil content. In contrast, the corresponding operating air velocity has little influence on the segregation of oil content, because the response surface shape is gentler along with the variation direction of air velocity. The segregation intensity increases to its maximum and then decreases as the vibration intensity increases, and the peak segregation intensity is achieved when the air velocity and the vibration intensity are $1.46 \mathrm{~cm} / \mathrm{s}$ and 10.87, respectively. The effect of the vibration intensity on the segregation intensity is more sensitive than that of the air velocity, as concluded above. The vibration intensity affects the segregation intensity more significantly than the bed height, as illustrated in Fig. 11(b). The segregation intensity of oil content is mainly influenced by vibration intensity, the response surface shape is gentler along with the variation direction of bed height. The maximum segregation intensity is achieved at a vibration intensity of 10.87 and a bed height of $85 \mathrm{~mm}$. The response surface similarly varies in the air velocity and bed height directions. This demonstrates that the effects of the air velocity and the bed height on the segregation intensity are comparable (Fig. 11(c)). However, the response surface shows greater concavity in the air velocity axis direction than in the bed height axis direction, which indicates that the effect of the air velocity on the segregation intensity is more significant. From the above analysis, the effects of the variables on the segregation intensity of the oil content from large to small is vibration intensity, air velocity, bed height.

The mathematical model for the segregation intensity is determined by a regression analysis. The influence of the parameters on the segregation intensity is vibration intensity, air velocity, bed height from big to small. The mathematical models are expressed in Eqs. (2) and (3).

Mathematical model in terms of factors of codes:

$$
\begin{aligned}
S_{0}= & 0.85+0.055 \times A-0.05 \times B+0.065 \times C-0.042 \times A \\
& \times B+0.038 \times A \times C-0.073 \times B \times C-0.073 \times A^{2} \\
& -0.18 \times B^{2}-0.17 \times C^{2}
\end{aligned}
$$

\begin{tabular}{|c|c|c|c|c|c|c|}
\hline Source & Sum of squares & df & Mean square & $F$ Value & $P$-value prob $>F$ & \\
\hline Mean & 7.16 & 1 & 7.16 & & & \\
\hline Linear & 0.078 & 3 & 0.026 & 0.95 & 0.4465 & \\
\hline $2 \mathrm{FI}$ & 0.034 & 3 & 0.011 & 0.35 & 0.7905 & \\
\hline Quadratic & $\underline{0.31}$ & $\underline{3}$ & $\underline{0.10}$ & $\underline{52.98}$ & $<\underline{0.0001}$ & $\underline{\text { Suggest }}$ \\
\hline Cubic & $\overline{0.011}$ & 3 & $\overline{3.650 E}-003$ & 5.45 & 0.0675 & Aliased \\
\hline Residual & $2.680 \mathrm{E}-003$ & 4 & $6.700 \mathrm{E}-004$ & & & \\
\hline Total & 7.59 & 17 & 0.45 & & & \\
\hline
\end{tabular}

Table 6

Models comparison and selection. 
Table 7

Results of analysis of variance for quadratic model.

\begin{tabular}{|c|c|c|c|c|c|c|}
\hline Source & Sum of squares & df & Mean square & $F$ Value & prob $>F$ & \\
\hline Model & 0.42 & 9 & 0.047 & 24.04 & 0.0002 & Significant \\
\hline A-Air velocity & 0.024 & 1 & 0.024 & 12.43 & 0.0097 & \\
\hline B-Bed height & 0.020 & 1 & 0.020 & 10.27 & 0.0150 & \\
\hline C-Vibration intensity & 0.034 & 1 & 0.034 & 17.36 & 0.0042 & \\
\hline $\mathrm{AB}$ & $7.225 E-003$ & 1 & $7.225 E-003$ & 3.71 & 0.0954 & \\
\hline AC & $5.625 E-003$ & 1 & $5.625-003$ & 2.89 & 0.1330 & \\
\hline BC & 0.021 & 1 & 0.021 & 10.80 & 0.0134 & \\
\hline$A^{2}$ & 0.022 & 1 & 0.022 & 11.44 & 0.0117 & \\
\hline $\mathrm{B}^{2}$ & 0.14 & 1 & 0.14 & 72.22 & $<0.0001$ & \\
\hline$C^{2}$ & 0.12 & 1 & 0.12 & 60.85 & 0.0001 & \\
\hline Residual & 0.014 & 7 & $1.947 \mathrm{E}-003$ & & & \\
\hline Pure error & $2.680 \mathrm{E}-003$ & 4 & $6.700 \mathrm{E}-004$ & & & \\
\hline Cor Total & 0.43 & 16 & & & & \\
\hline
\end{tabular}


(a)
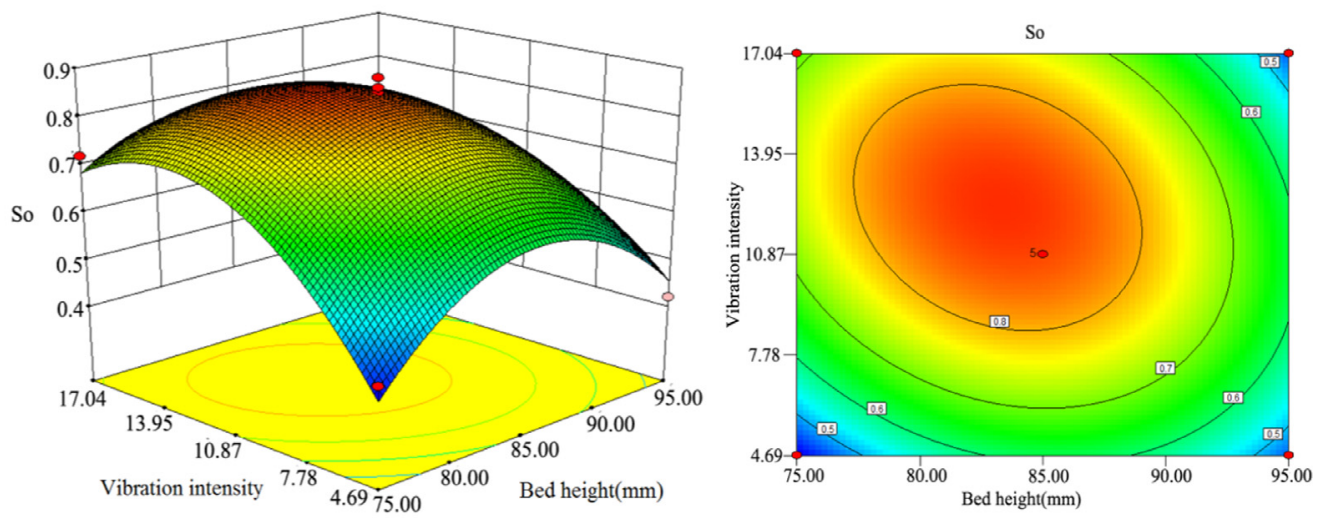

(b)
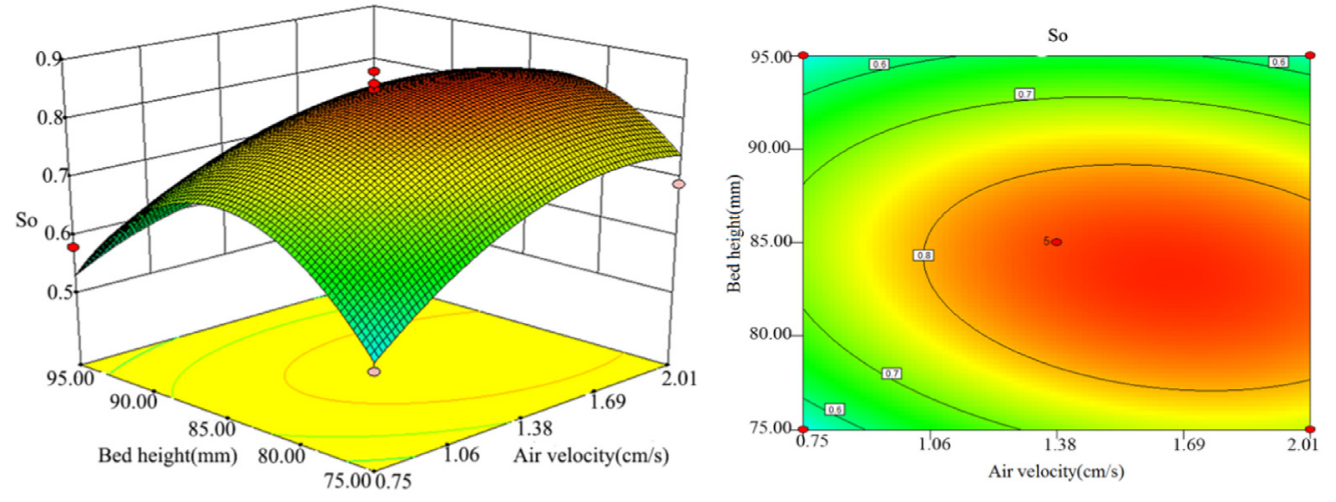

(c)

Fig. 11. Effects of operation parameters on beneficiation. 
where $A$ is the air velocity $(\mathrm{cm} / \mathrm{s}), B$ is the bed height $(\mathrm{mm})$, and $C$ is the vibration intensity.

Mathematical model in terms of actual operational factors:

$$
\begin{aligned}
S_{o}= & -14.77+1.06 v+0.33 h+0.19 \Gamma-6.75 \times 10^{-3} v h \\
& +9.64 \times 10^{-3} v \Gamma-1.17 \times 10^{-3} h \Gamma-0.18 v^{2}-1.83 \\
& \times 10^{-3} h^{2}-4.40 \times 10^{-3} \Gamma^{2}
\end{aligned}
$$

where $v$ is the air velocity $(\mathrm{cm} / \mathrm{s}), h$ is the bed height $(\mathrm{mm})$, and $\Gamma$ is the vibration intensity.

The comparison between the predicted value and the measured value calculated by Eq. (3) shows that the predicted value has a high degree of coincidence with the measured value. Thus, the model has high accuracy.

\subsection{Bed material distribution characteristics under optimal operating parameters}

The oil shale is sorted according to the density in the VADMFB. The distribution of the material in the bed directly affects the sorting accuracy. Therefore, the distribution of the bed material under the optimal sorting conditions is analyzed, and the distribution law of the material in the bed is obtained. The sorting parameters can be further optimized, and the sorting accuracy can be improved. In
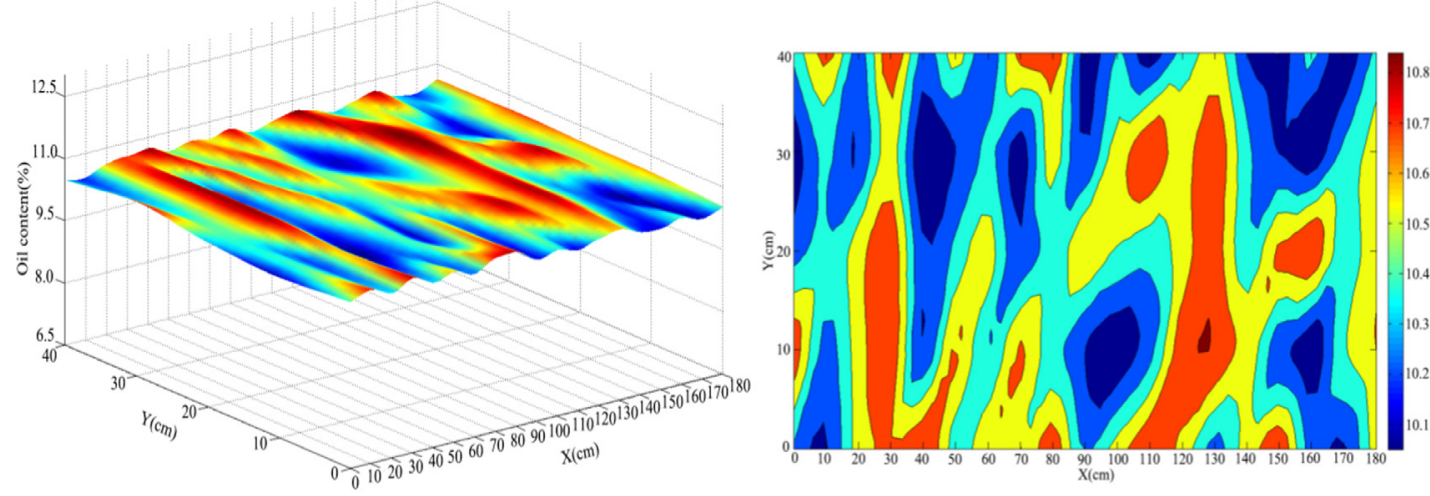

(I) Distribution of material oil content in upper layer
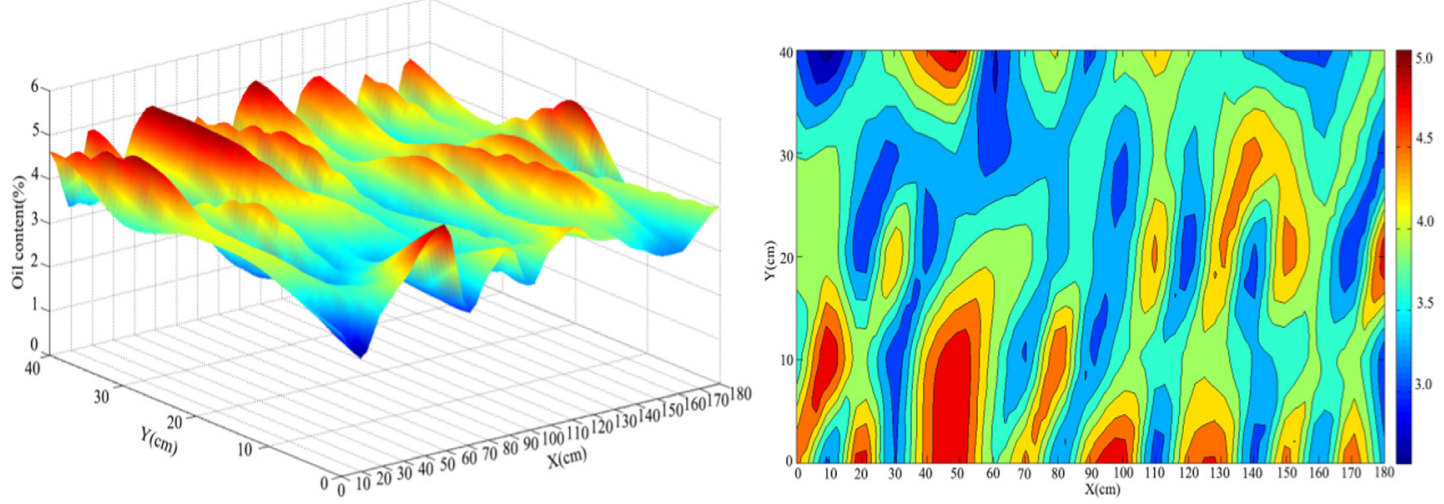

(II) Distribution of material oil content in middle layer
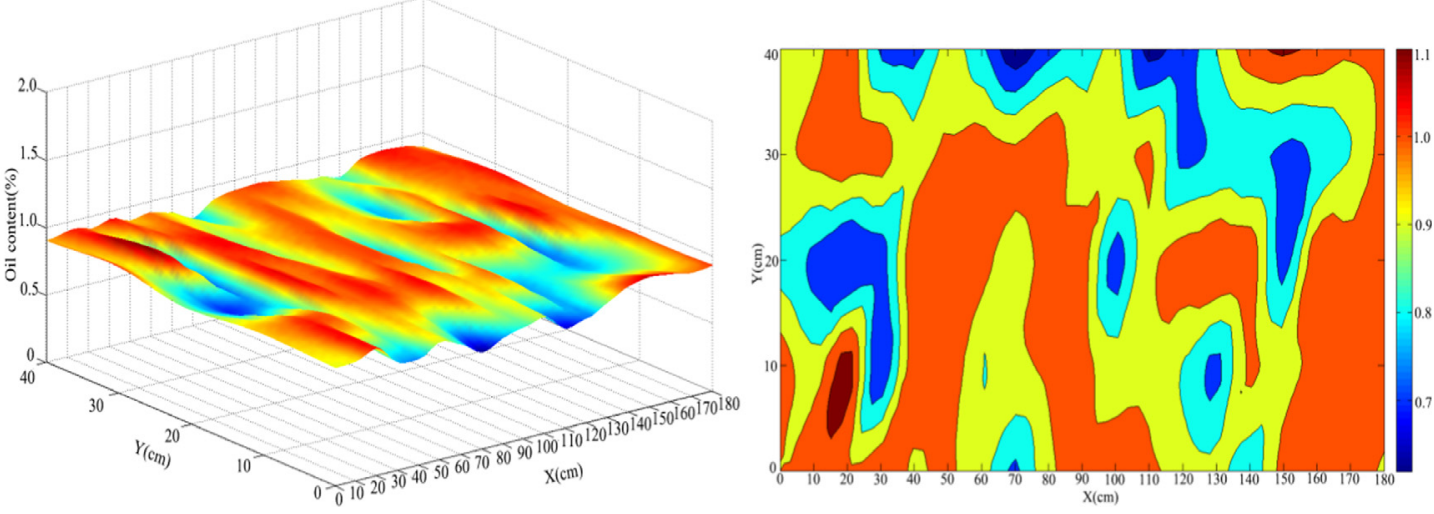

(III) Distribution of material oil content in lower layer

Fig. 12. (III) Distribution of material oil content in lower layer. 
Table 8

Partition coefficient results for 6-0 $\mathrm{mm}$ oil shale beneficiated using VADMFB separator.

\begin{tabular}{|c|c|c|c|c|c|c|c|c|}
\hline \multirow{2}{*}{$\begin{array}{l}\text { Density }(\mathrm{g} / \\
\left.\mathrm{cm}^{3}\right)\end{array}$} & \multirow{2}{*}{$\begin{array}{l}\text { Average density }(\mathrm{g} / \\
\left.\mathrm{cm}^{3}\right) \\
1.75\end{array}$} & \multirow{2}{*}{$\begin{array}{l}\text { Feedstock sink-float result } \\
(\%)\end{array}$} & \multicolumn{2}{|c|}{$\begin{array}{l}\text { Tailings sink- } \\
\text { float results } \\
(\%)\end{array}$} & \multicolumn{2}{|c|}{$\begin{array}{l}\text { Concentrate } \\
\text { sink-float } \\
\text { results (\%) }\end{array}$} & \multirow{2}{*}{$\begin{array}{l}\text { Calculated feed stock sink-float } \\
\text { results (\%) } \\
9.96\end{array}$} & \multirow{2}{*}{$\begin{array}{l}\text { Partition coefficient } \\
(\%)\end{array}$} \\
\hline & & & 1.55 & 1.07 & 28.55 & 8.89 & & \\
\hline $1.9-2.0$ & 1.95 & 3.48 & 1.00 & 0.69 & 9.02 & 2.81 & 3.50 & 19.71 \\
\hline $2.0-2.1$ & 2.05 & 3.25 & 1.07 & 0.74 & 7.26 & 2.26 & 3.00 & 24.67 \\
\hline $2.1-2.2$ & 2.15 & 1.87 & 1.44 & 0.99 & 3.24 & 1.01 & 2.00 & 49.50 \\
\hline $2.2-2.3$ & 2.25 & 3.81 & 3.47 & 2.39 & 4.66 & 1.45 & 3.84 & 62.24 \\
\hline $2.3-2.5$ & 2.40 & 11.71 & 13.08 & 9.01 & 7.77 & 2.42 & 11.43 & 78.83 \\
\hline+2.5 & 2.60 & 65.90 & 78.38 & 53.97 & 39.50 & 12.30 & 66.27 & 81.44 \\
\hline Total & & 100 & 100.00 & 68.86 & 100.00 & 31.34 & 100.00 & \\
\hline
\end{tabular}

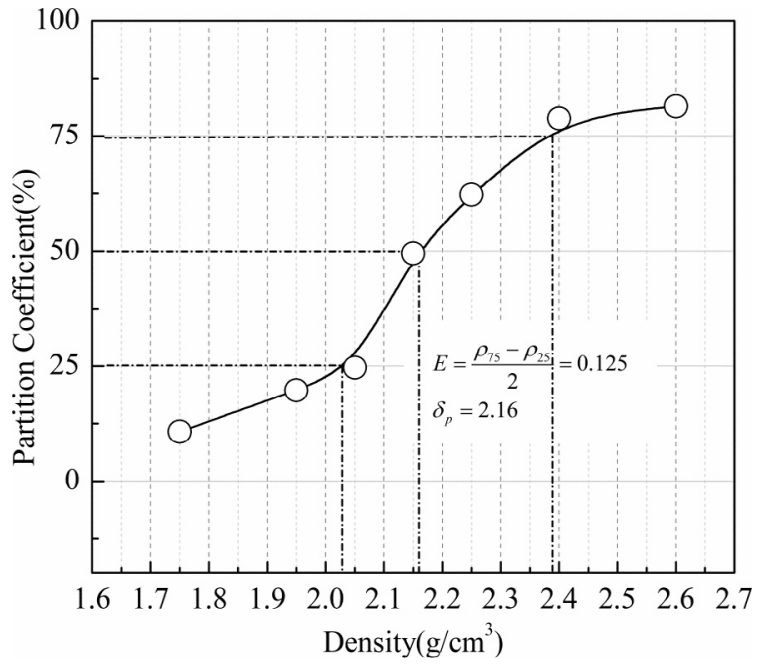

Fig. 13. Partition curves for VADMFB beneficiation.

this study, 6-0 mm oil shale is beneficiated under optimum operating parameters ( $v=1.46 \mathrm{~cm} / \mathrm{s}, h=85 \mathrm{~mm}, \Gamma=10.87$ ). At the same time, the oil content distribution in the upper, middle, and lower layers is analyzed, as shown in Fig. 12.

Fig. 12 shows the oil content distribution trajectories in the upper, middle, and lower layers in the VADMFB under optimum operating parameters. The figure shows that the material oil content distribution in the upper layer is smaller, and the oil content in the material fluctuates between $8 \%$ and $11 \%$. The oil content in the material fluctuates only in the intersection area of 65$110 \mathrm{~cm}$ in the $\mathrm{X}$-axis direction and $5-40 \mathrm{~cm}$ in the $\mathrm{Y}$-axis direction. However, the material in the entire bed shows a uniform distribution, which indicates that the surface material distribution is more uniform under the optimal operating parameters with stable concentrate quality. Fig. 12(II) shows that the fluctuation range of the oil content in the middle layer is larger than that in the upper layer and the oil content in the material fluctuates between $2.5 \%$ and $4.1 \%$. In the intersection areas of $0-80 \mathrm{~cm}$ in the $\mathrm{X}$-axis direction, $5-40 \mathrm{~cm}$ in the Y-axis direction, $140-170 \mathrm{~cm}$ in the X-axis direction, and $30-40 \mathrm{~cm}$ in the $\mathrm{Y}$-axis direction, the material oil content fluctuates inordinately. This indicates that the trajectory of the middle layer material is chaotic during the sorting process in the VADMFB with the occurrence of particle back-mixing. This is because the material is sorted according to the density. The stratification of higher and lower density materials in this layer is achieved, forming the transition layer of material separation. Fig. 12(III) shows the distribution of the oil content in the lower layer. The oil content in the layer is low with values from $0.4 \%$ to $1.1 \%$. However, the overall oil content distribution in the bed layer is relatively uniform. The oil content distribution fluctuates slightly only in the intersection area of $40-70 \mathrm{~cm}$ in the $\mathrm{X}$-axis direction and $15-30 \mathrm{~cm}$ in the Y-axis direction, which illustrates that the material with greater density and lower oil content is mainly concentrated at the bottom. The analysis of the oil content distribution in the upper, middle, and lower layers can fully explain the stability and reliability of the bed density in the VADMFB under the optimum operating parameters.

\subsection{Beneficiation results}

The effects of the beneficiation parameters of the VADMFB separator on the cleaning of $6-0 \mathrm{~mm}$ oil shale are systematically studied. A beneficiation test for $6-0 \mathrm{~mm}$ fine-grain oil shale using the VADMFB is performed under the optimized operation conditions ( $v=1.46 \mathrm{~cm} / \mathrm{s}, h=85 \mathrm{~mm}, \Gamma=10.87$ ). The oil content in raw ore is $3.96 \%$ when the actual sorting density is $2.16 \mathrm{~g} / \mathrm{cm}^{3}$, the separating accuracy (probable error $E$ ) is $0.125 \mathrm{~g} / \mathrm{cm}^{3}$, and the yields of the concentrate and tailings are $31.34 \%$ and $68.66 \%$, respectively. Moreover, the oil content in the concentrate and tailings is $10.65 \%$ and $0.92 \%$, respectively. The concentrate can be pyrolyzed to generate shale oil, gasoline, kerosene, diesel etc. and many other chemical products are obtained when the shale oil is hydro cracked. Then the products could be used for heating building and power generation. The partition coefficients and curves are presented in Table 8 and Fig. 13, respectively.

\section{Conclusions}

The effects of the vibration intensity, airflow and bed height on the VADMFB beneficiation of $6-0 \mathrm{~mm}$ oil shale were analyzed. A beneficiation test for $6-0 \mathrm{~mm}$ fine-grain oil shale was performed using the optimized operation parameters, and the material oil content distribution in the upper, middle, and lower layers of the separation bed was studied. The conclusions were drawn as follows:

(1) The effects of the parameters on the beneficiation of 6-0 mm oil shale by the VADMFB from big to small is vibration intensity, air velocity, bed height. The optimal operation parameters of the airflow $(v)$, bed height $(h)$, and vibration intensity $(\Gamma)$ are $1.46 \mathrm{~cm} / \mathrm{s}, 85 \mathrm{~mm}$, and 10.87 , respectively. Under these conditions, the materials in the upper and lower layers are evenly distributed with weak fluctuation and the material distribution in the middle layer is relatively chaotic.

(2) Under the optimum operating parameters, $6-0 \mathrm{~mm}$ oil shale was beneficiated by the VADMFB, and the yields of the concentrate and tailings are $31.34 \%$ and $68.66 \%$, respectively. Moreover, the oil content in the concentrate and tailings is $10.65 \%$ and $0.92 \%$ respectively, and the quality of the concentrate meets the user's refining requirements.

(3) The VADMFB separator can effectively beneficiate $6-0 \mathrm{~mm}$ oil shale. The oil shale can be recycled and utilized efficiently. 


\section{References}

[1] Jiang XM, Han XX, Cui ZG. New technology for the comprehensive utilization of Chinese oil shale resources. Energy 2007;32:772-7.

[2] Na JG, Im CH, Chung SH, Lee KB. Effect of oil shale retorting temperature on shale oil yield and properties. Fuel 2012;95:131-5.

[3] Lai DG, Chen ZH, Lin LX, Zhang YM, Gao SQ, Xu GW. Secondary cracking and upgrading of shale oil from pyrolyzing oil shale over shale ash. Energy Fuel 2015;29:2219-26.

[4] Dyni JR. Geology and resources of some world oil shale deposits. Oil Shale 2003;20:193-252.

[5] Wang S, Liu JX, Jiang XM, Han XX, Tong JH. Effect of heating rate on products yield and characteristics of non-condensable gases and shale oil obtained by retorting Dachengzi oil shale. Oil Shale 2013;30:27-47.

[6] Niu M, Wang S, Han XX, Jiang XM. Yield and characteristics of shale oil from the retorting of oil shale and fine oil-shale ash mixtures. Appl Energy 2013;111:234-9.

[7] Oja V, Elenurm A, Rohtla I, Tali E, Tearo E, Yanchilin A. Comparison of oil shales from different deposits: oil shale pyrolysis and co-pyrolysis with ash. Oil Shale 2007;24:101-8.

[8] Subasinghe ND, Awaja F, Bhargava SK. Variation of kerogen content and mineralogy in some Australian tertiary oil shales. Fuel 2009;88:335-9.

[9] Hughes JD. Energy: a reality check on the shale revolution. Nature 2013;494 (7437):307-8
[10] Guo WB, Tan Y, Bai EH. Top coal caving mining technique in thick coal seam beneath the earth dam. Int J Min Sci Technol 2017;27:165-70.

[11] Yun DF, Liu Z, Cheng WD, Fan ZD, Wang DF, Zhang YH. Monitoring strata behavior due to multi-slicing top coal caving longwall mining in steeply dipping extra thick coal seam. Int J Min Sci Technol 2017;27:179-84.

[12] Wang Q, Xu F, Bo J. Study on the basic physicochemical characteristics of the huadian oil shale. J Jilin Univ (Earth Sci Ed) 2006;36:1006-11 [in Chinese].

[13] Wei LB, Li DH, Chen ZG, Sun MY, Zhu XS. Numerical simulation of force and separation on particles in pulsing air flow. J China Univ Min Technol 2017;01. 0162-07.

[14] Gong YS, Tao YJ, Zhang L, Zhang WC. Density separation model enhanced centrifugal beneficiation for fine coal. J China Univ Min Technol 2017;01. 0177-06.

[15] Yu XD, Luo ZF, Yang XL, Jiang HS, Zhou EH, Zhang B, et al. Oil shale separation using a novel combined dry beneficiation process. Fuel 2016;180:148-56.

[16] Luo Z, Fan M, Zhao Y, Tao X, Chen Q, Chen Z. Density-dependent separation of dry fine coal in a vibrated fluidized bed. Powder Technol 2008;187:119-23.

[17] Yang X, Zhao Y, Luo Z, Song S, Duan C, Dong L. Fine coal dry cleaning using a vibrated gas-fluidized bed. Fuel Process Technol 2013;106:338-43.

[18] Yu XD, Luo ZF, Li HB, Yang XL, Zhou EH, Jiang HS, et al. Effect of vibration on the separation efficiency of high sulfur coal in a compound dry separator. Int J Miner Process 2016;157:195-204. 